\title{
Managing talent across advanced and emerging economies: HR issues and challenges in a Sino-German strategic collaboration
}

Article

Accepted Version

Stokes, P., Liu, Y., Smith, S., Leidner, S., Moore, N. and Rowland, C. (2016) Managing talent across advanced and emerging economies: HR issues and challenges in a SinoGerman strategic collaboration. The International Journal of Human Resource Management, 27 (20). pp. 2310-2338. ISSN 1466-4399 doi:

https://doi.org/10.1080/09585192.2015.1074090 Available at https://centaur.reading.ac.uk/81616/

It is advisable to refer to the publisher's version if you intend to cite from the work. See Guidance on citing.

Published version at: http://dx.doi.org/10.1080/09585192.2015.1074090

To link to this article DOI: http://dx.doi.org/10.1080/09585192.2015.1074090

Publisher: Routledge

All outputs in CentAUR are protected by Intellectual Property Rights law, including copyright law. Copyright and IPR is retained by the creators or other copyright holders. Terms and conditions for use of this material are defined in the End User Agreement. 


\section{www.reading.ac.uk/centaur}

\section{CentAUR}

Central Archive at the University of Reading

Reading's research outputs online 


\section{HR Talent management practices in developed economy SMEs operating in emerging economies: issues and challenges in a Sino-German strategic collaboration}

Peter Stokes ${ }^{\mathrm{a}}$, Yipeng Liu ${ }^{\mathrm{b}}$, Simon Smith ${ }^{\mathrm{c}}$, Sarah Leidner ${ }^{\mathrm{d}}$, Neil Moore ${ }^{\mathrm{e}}$, Caroline Rowland ${ }^{\mathrm{f}}$

a'University of Chester, University of Chester Business School, Chester, United Kingdom; ${ }^{b}$ University of Birmingham, Birmingham Business School, Birmingham, United Kingdom; ${ }^{c}$ University of Chester, University of Chester Business School, Chester, United Kingdom; dUniversity of Southampton, Southampton Business School, Southampton, United Kingdom; 'University of Chester, University of Chester Business School, Chester, United Kingdom; ${ }^{\mathrm{f}}$ University of Chester, University of Chester Business School, Chester, United Kingdom. 


\section{HR Talent management practices in developed economy SMEs operating in emerging economies: issues and challenges in a Sino- German strategic collaboration}

The HR practices involved in talent management are an important HRM issue for all organisations. A majority of talent management writing is from multinational corporation perspectives (MNC). However, the less commented small-to-medium sized enterprise (SME) also confronts challenges grounded in economic (i.e. resources, finance), organisational (linked to size, scope and structure) and consequent behavioral rationales (connecting with mindsets and stances). The paper establishes and examines a number of propositions which explore how these factors impact on advanced economy SME talent management HR practices within emerging economy collaborations.

The paper employs an interpretive qualitative methodology using interviews conducted within two cases - SME and an MNC comparator case. The findings indicate that: the SME initially adopted a normative planned approach but rapidly turned to develop localised and serendipitous HR practices in response to talent management challenges; was predicated towards a configuration of short-term expatriate visits and inpatriates; and, experienced ongoing acculturisation-reacculturation oscillation.

Keywords: HR practices, talent management, SME, inpatriate, acculturisation. 


\section{Introduction}

Human Resource (HR) practices around talent management - the recruitment, selection and retention of national and international talent by organizations - has attracted considerable scholarly attention (Collings, Scullion and Morley, 2007; Farndale, Scullion and Sparrow, 2010; Minbaeva and Collings, 2013). This work has focused primarily on HR practices in multinational corporation (MNC) contexts. This propensity is perhaps to be anticipated since MNCs possess complex multi-faceted infrastructures, expansive international operations, and, large marketing budgets which require (and can afford) the development of planned talent management systems.

In contrast, by definition, small to medium-sized enterprises (SMEs), frequently lack the scale, scope, resources and international experience of MNCs. In essence, while SMEs may compete in segments of MNC markets, the 'world' of SMEs in terms of inter alia: decisionmaking, investment choices, culture and daily running of the firm - often led by family owner-directors and linked with a community rooted to a specific geographical locality - are all substantively different to MNCs. In response to SME proclivities, a substantive body of writing has been generated (Voordeckers, Van Gils and Van de Heuvel, 2007; Nieto, Santamaria, Fernandez, 2013; Lewis, 2015). Nevertheless, HR practices for talent recruitment and management in SMEs, and in particular as SMEs expand into international strategic partnerships, have been considerably less researched.

Given the above-noted prima facie differences between SMEs and MNCs, talent management HR practices in MNCs cannot necessarily be considered to provide an automatic template or ready-made solution for SME operational questions. Talent management for an SME is, in any circumstances, a substantial task, however, for SMEs operating in emerging markets additional challenges can be anticipated - moreover, it has been noted that any problems are accentuated by an existing paucity of global talent (Farndale et al. 2010). While MNCs tend to adhere to standard HR expatriate practices in order to deal with talent management challenges (Cerdin and Brewster, 2014; Al Ariss, 2014), SMEs experience, and have to address, HR practices for talent management in alternative ways. Nevertheless, there is, in general, a paucity of understanding around advanced economy SME (AE-SME) HR practices for talent management and even less is commented on AE-SME talent management within 
international collaboration, and especially emerging economy, contexts. This leads to the following research question:

How do economic, organisational and behavioral rationale operate on AE-SME talent management $\mathrm{HR}$ practices in international collaborations in emerging market contexts?

The paper is structured as follows: firstly, the argument defines and outlines extant understandings of HR practices and issues on talent management and the predominant position of MNCs. The argument then theoretically constructs the specific situation of SMEs in relation to economic, organizational and behavioral rationale which drive talent recruitment practices with specific reference to situations surrounding expatriates and inpatriates. Subsequently, the argument details and justifies the methodology employed by the paper developing SME case study primary data. These comprise a series of vignettes which illustrate the HRM challenges confronted by an AE-SME undertaking collaborative arrangements in the emerging market of China. This is complemented and counterpointed by a comparator advanced economy MNC (AE-MNC) case from a similar sector. The paper signals a range of practices and factors which characterise the situations in relation to the SME collaborative experience of talent management in an emerging market context.

\section{Talent Management - Background}

In recent years, talent management, which is founded on the underlying assumption that identifying, recruiting and managing talent can enhance organisational performance and business results (Lockwood, 2006), has become a central aspect of HR practices. One of the early advocates of talent management was Steven Hankin of McKinsey \& Co who proposed the term 'War for Talent' in 1997 (Agrawal, 2010; Collings and Mellanhi, 2009). Talent management has evolved from a need to rethink, and respond to, conventional views on HR employee planning and recruitment in the face of continuously changing local and global circumstances. There are many working definitions of talent management, however for the purposes of discussion, it can prima facie be understood as: 
'...the systematic attraction, identification, development, engagement/retention and deployment of those individuals with high potential who are of particular value to an organization' (Iles, Chaui and Preece, 2010).

It is important to acknowledge the non-uniform, variable and disparate nature of many talent markets. Nevertheless, although talent markets are often dynamic, it is equally significant not to assume that talent will always be inherently or automatically internationally mobile (Collings, Scullion and Morley 2007; Collings, Doherty, Osborn and Luethy 2011; Hippler 2009). For example, talent may, on occasion, be fixed in, or attached to, a relatively small geographical area or equally, the supply of, and demand for, talent may not be evenly distributed across geographic areas resulting in mismatches in supply and demand:

'Thus for many organizations there now seems to be a talent surplus with unemployment increasing across many countries and too many qualified people chasing too few jobs' (Tarique and Schuler, 2010).

Talent management can be challenging in many ways, however, in particular, the rapidly transforming dynamics of emerging markets bring fresh challenges. Emerging economies are often associated with fragmented labor markets and a lack of high quality labor supply (Cooke, 2009). Moreover, there may be significant institutional differences between emerging markets and advanced economies as illustrated in, for example, the varying function of labor union exhortations to foreign SMEs to understand the 'rules of the game' (Xing, Liu, Tarba and Cooper, 2014). Furthermore, rapid employee turnover in emerging markets can create instability in the composition of a small SME workforce and raise concerns over the continual need to recruit and select qualified employees (Warner, 2012; Zhu, Thomson and Cieri, 2008).

However, as a general rule, expanding economic activity in high growth emerging markets, means that talented individuals have little difficulty in securing employment. This, nevertheless, leads to what Meyskens et al (2009) refers to as a paradox: that within the forces of globalisation it should be anticipated that the quantity of global staff with multiple talents (following Furusawa and Brewster, 2014) will indeed expand but equally may well be harder to retain: 
'While international talent grows in value, it is increasingly difficult to obtain, deploy and retain. Globalization and demographics all but ensure the paradox will grow in complexity’ (Meyskens, Von Glinow, Werther, and Clarke, 2009).

Such variations in talent markets can represent considerable impediments for any firm. MNCs, due to their absorptive capacity, resource flexibility are perhaps more likely to be able to overcome such international market fluctuations and regional variances. However, SMEs do not commonly possess the depth of economic resources and organisational operations to, for instance, switch staff easily between international locations. In spite of these differences, much of the commentary on talent management has focused predominantly on MNC contexts. This is likely to have important implications for HR practices for talent management. Moreover, where it is an AE-SME operating collaboratively in an emerging market this raises yet further issues and these are explored in the next phases of the argument.

\section{HR Practices in Talent Management: The Case of SMEs in Relation to MNCs}

The predilection of the extant literature and theory development for HR talent management practices to focus on MNCs (as opposed to SME contexts) is, to some degree, to be expected given the innate international nature, the large multi-country and multi-market scale and scope of MNC operations. Nevertheless, SMEs are a highly important aspect of the global economy and merit attention for a number of reasons. In 2010, a survey of 132 countries estimated that there were 125 million micro, small, and medium enterprises, 89 million of which were located in emerging markets (IFC - World Bank, 2013). Thus, it is of little surprise that aspects of SME operations have generated research in a wide range of focal research areas including, inter alia: SME growth patterns; managerial styles; business cycles and behaviour and attitudes (see Penrose, 1959; Handy et al. 1988; Stanworth and Gray, 1991; Beaver, 2002; Wilson and Thomson, 2006; Lappelainen and Niskanen, 2014). From the early phases of SME research, the error of assuming that SMEs were simply scaled down versions of larger enterprises was recognised:

'..the differences in the administrative structure of the very small and the very large

firm are so great that in many ways it is hard to see that the two species are of the 
same genus...we cannot define a caterpillar and then use the same definition for a butterfly' (Penrose, 1959: 19).

In this vein, Handy et al (1988: 47) observed that SMEs are different in a range of ways when compared with their larger counterparts suggesting that the constraints and uncertainties faced by SMEs tend to be substantively different from those faced by large-scale enterprises. Furthermore, Stanworth and Gray (1991: 15) argued that small businesses experience a range of unique problems and issues that are simply not applicable to their MNC counterparts (including most evidently for example, economic resource poverty). More contemporaneously, the theme of SME distinctiveness has prevailed with Stokes and Wilson (2006: 327) drawing more precise focus on SME internal processes: 'Managing in a small business is not like managing part of a large organisation.' Similarly, Beaver (2002: 60) suggests that:

'Management processes in small firms are unique. Much of the contemporary theory is founded upon the empirical analysis of managerial action in large organisations [emphasis added]. These principles, no matter how refined, cannot be applied directly to small enterprises. While common skills need to be in evidence in many organisations, the contextualisation of these skills to meet the requirements of the small business operating environment is distinctive.'

Thus, given these differences, it is reasonable to assert that talent management HR practices in MNCs cannot automatically be transferred to SMEs (Valverde, Scullion and Ryan, 2013). Where AE-SMEs are operating in partnership or collaborative arrangements in emerging market settings these practices are likely to be more complex and variegated and as a consequence necessitate innovative management responses. The next section of the discussion develops the theoretical understanding of SME contexts and begins to identify the impact on talent management.

Economic, Organizational and Behavioral Rationale of SMEs: Implications for HR Talent Management Practices. 
As identified above, the issues, constraints and uncertainties surrounding SMEs (including challenges in the area of talent management practices) represent a significant issue that may hinder SME growth development (Unger, Rauch, Frese, and Rosenbusch, 2011). Within the present paper, we develop and explore the above tensions through a theoretical framework of economic and organisational rationales. These act as independent variables operating on the third, dependent behavioral rationale. Firstly, from the economic perspective, SMEs are prone to experiencing severe resource constraints which preclude the ready transfer and deployment of standard MNC talent management HR practices to SMEs. As a consequence of general resource scarcity in SMEs (Gray, 2004: 454) the allocation of limited resources is prioritised in terms of those functions that are perceived to be the most valuable. Thus, most often key HR domains, such as talent recruitment and selection, are potentially underresourced in favour of marketing, finance and production activities (Harrison, 2002: 228; Mazzarol, 2003: 31; Kotey and Slade, 2005: 18; Barret and Mayson, 2007: 309). Therefore, economically, the SME, by the very limited nature and scope of its operations, does not generally have the automatic resources or geographic reach of operations available to the larger firm and this shapes its approach to issues such as talent management.

Secondly, from the organisational rationale, SMEs, in contrast to MNC-style enterprises, do not generally establish complex, hierarchical and expansive organisational structures and this too has important implications for talent management. Furthermore, the perception of SME owners and managers towards HR practices and issues is contingent upon the stage of organisational evolution. For example, an extensive empirical analysis of 1,693 SMEs demonstrated that owner and managers running more evolved, larger, SMEs were more likely to perceive acute HR problems (Tocher and Rutherford, 2009). In addition, unlike the generally highly planned and systematised structures of MNCs, the flow and control of work and information tend to be informally organised and organisational design processes are generally organic, rather than consistently planned and ordered. This does not preclude planned approaches but the informal and reactive is likely to be privileged and operated in tandem with planned stances. As a consequence, SME management and HR practices are typically flexible, unconventional and best described as being ad hoc in nature (Thorpe et al. 2008: 29; Hutchinson and Quintas, 2008: 139). When applied to talent management, SME organisational dimensions mean that an SME approach is much more likely to adhere to informal, organic and flexible approaches in contrast to the more formal, systematised, procedural, planned and normative postures adopted by MNCs. Thus, HR practices for talent 
management under SME conditions can be anticipated to have significant differences to the manner in which it operates within MNC contexts.

Importantly, the economic and the organisational rationales, and their attendant constraints combine to produce, or generate, a third rationale which is behavioral. Importantly, the argument proposes that this third rationale encompasses two predispositions; spatialattitudinal predispositions and temporal-attitudinal predispositions. Behavioral SME spatialattitudinal predispositions are associated with given mindsets and prevailing belief systems often connected to a particular place or local, for example, the region in which the SME is situated - in the SME employees' experience. Alternatively, behavioral SME temporalattitudinal predispositions point at particular action-orientations occurring over given periods of time in SME contexts (for example, flexibility, ad hoc decision making, shorttermism). Alternatively expressed, spatial-attitudinal predispositions tend to exhibit more 'fixed' and established traits and be involved with sense-making (Weick, 1995) around 'place' while temporal-attitudinal pre-dispositions are characterised by rapid change and dynamic environments.

Behavioral SME spatial-attitudinal predispositions (associated with mindsets and belief systems) point at a propensity towards informality in HR practices in SMEs (including talent management) rather than adherence to the more formal processes in larger organizations (Bacon and Hoque, 2005). That is to say, HR practices in SMEs are often emergent underlining the complexity and heterogeneity of HR in SME settings (Harney and Dundon, 2006). Nevertheless, within HR practices, talent management in SMEs tends to adopt an inclusive approach (i.e. it is potentially for all) as compared to large multinational enterprises where a more elitist selective approach is preferred (Festing et al., 2013). However, a key mindset may be a general reluctance to change which remains a perennial issue in the SME sector. Burns (2001: 23) suggested that SMEs tend to be suspicious of outside influences and reluctant to embrace new initiatives. As a result they are often risk being introverted, closedminded and may lack alacrity in responding to new opportunities. In contrast, managers favor 'tried and tested' methods and look inside the organisation for solutions to their problems and this reproduces habitual behavior. Thus, a spatial-attitudinal predisposition may pose a particularly difficult challenge for SME recruitment, selection and retention of talented employees. For instance, according to Stanworth and Gray (1991), SMEs find it difficult to attract managers of the appropriate calibre because they cannot offer high salaries and 
provide attractive career pathways. Nevertheless it should be noted that a study of 700 SMEs in Germany revealed that SMEs tend to undertake a cooperative approach in collaborating with other firms in order to overcome resource constraints (Festing, Schäfer, and Scullion, 2013).

The second aspect of the behavioral dimension embraces what can be described as a set of temporal-attitudinal predispositions. SMEs, being prone to using short planning horizons, are more likely to be focused upon immediate issues rather than medium and longer-term matters. This approach can produce management practices played out with short-termist and reactionary thinking. For instance, decision-making in SMEs is often geared towards dealing with immediate operational matters, rather than considering longer-term strategic issues (Gelinas and Bigras, 2004: 270. This means that talent management actions may prima facie espouse planned HR approaches but ultimately operate as iterative and be more akin to 'muddling through' (Lindblom, 1959). For instance, SMEs are synonymous with insecurity of tenure and limitations in terms of fringe benefits, such as health care and pension provision and these effects do not work well to retain talent. In summary, the economic, organisational and behavioral rationale combine to provide the conceptual framework in Figure 1:

Figure 1: Theoretical Framework: SME Shaping Rationale and Resultant Attitudinal Predispositions on HR Practices

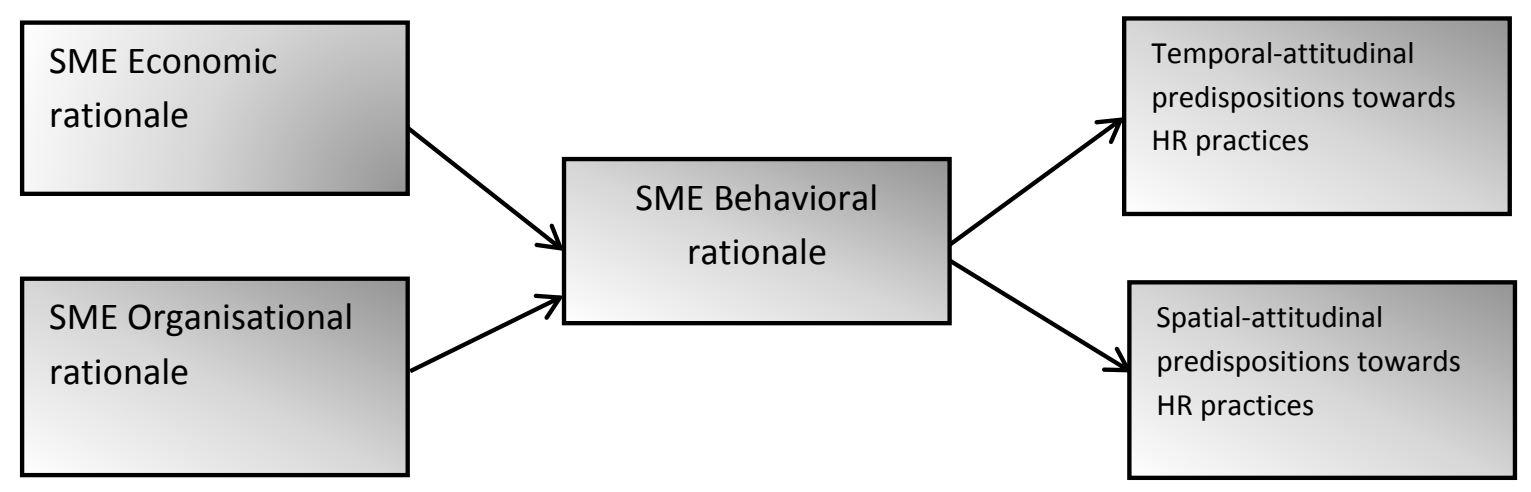

For AE-SMEs, forming collaborations in emerging market contexts, the above economic, organisational and behavioral rationale and predispositions potentially accentuate the challenges to be addressed with regard to talent management. Therein, it is necessary to manage the fusion of differing national and organisational cultural dimensions, whilst 
simultaneously managing the challenges of entering a contrasting set of market conditions and settings.

Following the economic, organisational and behavioural framework outlined above, from the perspective of the economic rationale, AE-SME owner-directors do not necessarily have the resources of time, expertise and finance at their disposal to recruit, select and retain talented employees with the specialist skills required to engage easily in emerging economy operations. Moreover, talent management within cross-cultural collaborations will vary substantially country-by-country and region-by-region calling for an extensive knowledge base and coverage which may be difficult and expensive to build up or acquire for an AESME. Equally, from the perspective of the organizational dimension, AE-SMEs do not have the scale or hierarchical structures to mount and sustain highly planned talent recruitment and management operations. Therefore, they need to employ approaches which correspond which the more informal, organic and flexible temporal-attitudinal predispositions of the firm. In relation to the behavioral dimension, firstly, the development of the spatial-attitudinal predisposition suggests that, in conjunction with the economic and organizational imperatives, AE-SME talent management HR practices in emerging economy collaborative contexts are likely to exhibit emergent, informal, inclusive (rather than elitist) approaches which react to complex and heterogeneous environments through largely tried and tested methods in which AE-SMEs may feel more secure. Secondly, through the temporalattitudinal predisposition, SMEs are likely to undertake talent management HR practices in a spirit of short planning timeframes resulting in immediate, iterative and to some extent shorttermist and reactionary. These arguments give rise to the first proposition of the paper:

Proposition 1: AE-SME HR talent management practices in emerging economy collaborations have a propensity, initially, to emulate MNC-style 'normative planned' approaches but AE-SME economic rationale rapidly (in a behavioral temporalattitudinal predispositions) drive the approach towards organic and changeable serendipitous approaches following SME that deliver responses based on spatialattitudinal predispositions.

\section{Collaborative partnership and HR practices}


Inter-organizational collaborative partnership constitutes an important organizational form (Gomes, Weber, Brown, and Tarba, 2011; Weber, Tarba, and Oberg, 2014). It offers the possibility for firms to address organizational and economic factors, thus in turn affect the HR practices from a behavioural perspective. Considering mergers and acquisitions as an example, HR practices remain a salient issue affecting M\&A performance (Weber and Tarba, 2010; Weber, Tarba, and Reichel, 2011), and integration process (Weber and Fried, 2011a). For instance, the dynamic reactions of employees in collaborative partnership can provide the resources to address organizational and economic issues collectively (Weber and Fried, 2011b; Teerikangas, 2012). Furthermore, different leadership styles may affect HR talent retention during M\&A integration (Zhang, Ahammad, Tarba, Cooper, Glaister, and Wang, 2015).

The above needs and pressures for firms associated with talent management have given rise to a range of intermediaries including the rise of, for example, the executive search firm (Cappelli and Hamori, 2014; Bonet, Cappelli and Hamori, 2013). The presence of third parties can have substantial effects on recruitment outcomes and dynamics (Breaugh, 2013). For example, Preece, Iles, and Chuai, 2011 warn of the risks of being provided with packaged rather than customised solutions. Such outcomes may in fact be a greater risk for MNCs than AE-SMEs as the former follow trends, fashions and emulate and reproduce kindred corporatized models. AE-SMEs, given specific geographic origins and specificities may be more reluctant to incur costs inclined to individual and idiosyncratic approached. Above all, third parties may be in strong positions to provide information and experience relating to diverse international settings that are simply not available to some firms (Collings, 2014). This leads to the second proposition of the argument:

Proposition 2: A combination of AE-SME economic and organizational rationales drive AE-SME HR talent management practices in emerging economy collaborations grounded in behavioral spatial-attitudinal stances which lean towards highly localised and proximate agency arrangements.

SME HR Practices for Expatriates and Inpatriates. 
A key decision for AE-SME firms entering emerging market environments is whether to use 'expatriates' and, or 'inpatriates'. Expatriates are individuals with specific talent sets who are sourced from a particular country or cultural context and brought into a different country and culture (Cerdin and Brewster, 2014). Alternatively, inpatriates are the talented individuals who are sourced from within a given cultural context to work in that setting. Al Ariss (2014) identifies a number of potential issues in comparing inpatriates and expatriates. Locals or inpatriate nationals may be less likely to work and socialise with expatriates. This may be attributed to underdeveloped globalised HR practices in an organisation, however, in any event, a lack of workforce cohesion is likely to have important negative impacts of organisational performance with resultant economic consequences. Furthermore, Cerdin and Brewster (2014) raise the issue of expatriates not having a sense of local identity in the expatriate destination, and therefore ultimately often not realising their high potential. In order to overcome these challenges, Collings et al. (2007) suggest alternatives to longer-term international assignments, including short-term assignments and more frequent international business travel. Moreover, much of the literature on expatriates underlines that many develop substantial career capital from international assignments (Stahl et al. 2002; Jokinen et al. 2008). However, with resonance for the present study, Suutari and Brewster (2003) identified that Chinese expatriates, for example, develop little career capital. Thus, in summary to these indicative insights, Harvey et al, (2010) and Harvey, Mayerhofer, Hartmann, and Moeller (2010) indicate that globalisation makes expatriate staffing in emerging markets a challenging question for companies of all sizes with issues of, among others: finding managers with experience in emerging markets; avoiding prohibitive costs; and, having the capacity to establish family and private lives for a substantial period of time. In the specific case of the AE-SME the above issues lead to the establishment of proposition 3:

Proposition 3: AE-SME economic rationale predicate temporal-attitudinally rapidly switching AE-SME HR talent management strategies in emerging market collaborations resulting in spatially attitudinally informed (i.e. local) solutions based on inpatriates and short-term expatriates.

Leading on from proposition 3, inpatriates can work as a useful alternative option to expatriates. However, Harvey et al (2010) note: 'There has been much less attention given to the evolving staffing options of flexipatriates and inpatriates'. Use of inpatriates is an increasing trend within international talent management (Reiche, 2006). Farndale et al. 
(2010) suggested a number of drivers for this including issues relating to the non-blanket usage of expatriates and engagement within a targeted variety of international marketplaces. However, the value of engaging host country national inpatriates is often underestimated by some MNCs (Harvey, Speier, and Novicevic, 1999). Inpatriates bring with them a number of evident advantages including: an awareness of their own culture and national environment; an ability to contextualise the company's operations to that environment; possession of their own network in the given country; and, providing an important and useful interface between the home country headquarters and the country branch (Harvey et al, 2010).

There is also an implication that a process of acculturisation by emerging market inpatriates blending with advanced economy firm national cultural norms may be anticipated. However, equally, such changes in behavior may be more transitory and less permanent than may first appear. Thus, particularly in AE-SME contexts - which do not have the economic and organisational resource and infrastructure of $\mathrm{MNCs}$ - it may be possible to postulate a tendency towards processes of acculturation and re-acculturisation leading to forms of inpatriate cultural 'oscillation'. This echoes some of the observations and insights provided by more critical management strands of the literature which point up the flexibility, ambiguity and complexity of identities at play in contemporary organisational contexts (Linstead, Lilley and Fulop, 2009; Stacey, 2010; Shaw 2010; 2012; Stokes, 2011). These ever-fluid environmental factors cause, in turn, challenges for the identity of inpatriates. Cognisance of these issues leads to the formulation of proposition 4:

Proposition 4: AE-SME organizational rationale have a propensity to induce a behavioral temporal-attitudinal pattern of inpatriate cultural oscillation' - wherein toand-fro movement between 'acculturisation' and 're-acculturisation' is prevalent driven by competing cultural spatial-attitudinal predispositions.

The paper now moves on to consider the focal primary data which point up in greater detail many of the issues confronting AE-SME talent recruitment and management. The argument also responds to a need for variegated data in relation to national and cultural contextual factors by considering advanced economy MNC and SME, the focal AE-SME case considering a German and Chinese collaboration. 


\section{Research Methodology and Methods}

The research question and propositions of the argument are grounded in an inductive research methodology. This approach facilitates the development of rich and exploratory contextual comparative data on AE-SME and MNC HR talent management practices when operating in an emerging market context (Bryman and Bell, 2011; Eriksson and Kovalainen, 2008; Kramer, 2006). This design allows a conceptual and theoretical framework to be developed, which articulates the assumptions and boundary conditions surrounding the comparative case study approach (Siggelkow, 2007, Edmondson and McManus, 2007). As a method, case studies are conducive to theory building endeavours (Eisenhardt and Graebner, 2007) and therefore are relevant to the present argument.

The AE-SME case focuses on a German SME working in partnership in China to recruit talent to its expanding operations (Yin, 2013). Following Siggelkow's (2007) recommendation that cases need to respond with particular questions and conditions, the AESME case demonstrates value because it offers a rare instance of seeing developed economy SME talent management in an emerging economy partnership. The AE-MNC works to provide a comparator case from a similar advanced and business sector context. Whilst the exogenous factors impinging on a company are commonly self-evident and visible to observers (for instance, the impact of economic changes, government policy and adjustments fiscal and supply-side measures, and, industry competitive pressures), Siggelkow (2007:21) notes that rare cases allow the endogenous (HR) practices and processes at play in these contexts to be surfaced and conceptualised. Again, kindred to Siggelkow (ibid), the intention of identifying a novel case is to motivate, illustrate and inspire similar research. The AE-SME case is complemented by a secondary comparative case of an advanced economy Europeanbased industrial MNC. The AE-MNC operates in the spare part machining and merchandising sector which is comparable to the machine-tool-sector operated in by the German-based SME. This case provides a developed economy MNC talent management context against which to compare and juxtapose the emergent novel data from the advanced economy SME case. As such, the AE-MNC case provides contrasting context in relation to the organizational, economic and behavioral rationale. 
Within the two case studies, a combination of face-to face and remote interviews (due to distance issues) were conducted. The in-depth face-to-face data were collected through semistructured interviews (Maylor and Blackmon, 2005:225-33; Gubrium, Holstein, Marvasti and McKinney, 2011) In the SME these were conducted with senior managers who were responsible for overseeing the recruitment and selection of talented inpatriates for the Chinese operations. These interviews included a series of six in-depth interviews with the CEO of the German SME who was also the overall lead for international recruitment activities. Access for the interviews was secured in Germany when the executives were not working in China. These data were supplemented with a series of telephone interviews with four key Chinese inpatriates working in the partnership operation in China who were accessed during visits to Germany. The interview process took into account issues of reflexivity at play in surfacing the data (Alvesson and Sköldberg, 2009). The data have been discussed and revisited with repeated readings and re-readings in order to clarify and confirm their representation of situations and approaches. Triangulation of the stories has been achieved by considering accounts provided by a further three key German members of staff engaged in international activities (Silverman, 2010: 275-278; Cameron and Price: 216-219). In the comparative case of the industrial MNC the semi-structured interviews were conducted with five executive managers and three senior managers who had undertaken or organised assignments in emerging economy contexts with a range of overseas partners, including a number in China.

\begin{tabular}{|l|l|l|}
\hline SME & & \\
\hline & CEO (x6 interviews) & 1 \\
\hline & Sales Director & 1 \\
\hline & $\begin{array}{l}\text { German Office Staff } \\
\text { (based in Germany) }\end{array}$ & 3 \\
\hline Chinese Inpatriates: \\
$\begin{array}{l}\text { General Manager } \\
\text { Sales Manager } \\
\text { Accountant }\end{array}$ & 4 \\
\hline MNC & $\begin{array}{l}\text { Executive Managers } \\
\text { (4 non-HR and 1 HR) }\end{array}$ & 5 \\
\hline
\end{tabular}




\begin{tabular}{|l|l|l|}
\hline & $\begin{array}{l}\text { Senior Managers } \\
(1 \text { non-HR and 1 HR })\end{array}$ & 2 \\
\hline & Executive Manager HR & 1 \\
\hline & Senior Manager - HR & 1 \\
\hline
\end{tabular}

Table 1: List of Interviews Conducted.

Overall, following Langley, Smallman, Tsoukas and Van de Ven (2013), the argument adopted a process study approach, collecting primary research data with which to unpack the dynamics and complexity of the situations encountered. This enabled strands of narrative and storytelling approaches in the data collection (Czarniawska, 1998; Gabriel, 2000, 2004; Phillips and Oswick, 2012). Narrative-style data and analysis can produce rich information and insights on strategic partnership topics, such as intercultural influences managerial behaviours (Xing, Liu, Tarba and Cooper, 2014), post-merger integration (Monin, Noorderhaven, Vaara and Kroon, 2013), national culture influence on foreign MNC local employees (Caprar, 2011).

\section{The Case Studies}

\section{The SME Case Study}

The first case study company is an SME which produces precision machine tools for the metal working industry and is located in southern Germany. It employs 130 people. It has been established for 40 years and trades in a range of international markets across Europe, Northern America and Asia. The firm produces machine tools for end-users and a significant part of its business is as an original equipment manufacturer (OEM). OEMs are companies which make the definitive and authentic products for a particular brand (Feng, 2014). The company sells its products and provides after sales services, such as product repair and maintenance, to a range of customers located in overseas markets, including China. In such markets repeat business is crucial and as a result it is essential that sales and after sales service are very reliable and of the right quality. In order to achieve the highest quality and protect its intellectual property the firm has chosen to employ local representatives rather than relying upon third-party distributors. 
In 2010, the German SME took the decision to enter the Chinese market. It did this by setting up an operation in Shanghai, China. After an initial unsuccessful attempt to recruit a local Chinese employee through a third party agency the CEO opportunistically approached a local German university to attract applications from inpatriates. The experience of managing the recruitment process in this way resulted in a range of specific talent management issues in relation to strategic partnership and cultural contextual factors.

\section{The MNC comparator Case Study}

The MNC organization is a European-based corporation operating in the international vehicle spare parts and machine tool markets. It employs approximately 9,000 employees worldwide and has coverage of a range of developed and emerging markets including China in which it has been operating for 14 years.

The MNC employs an extensive variety of nationalities. The HR function is charged with creating and managing an active expatriate programme to support the business needs of the company. There is an expectation in the organisation that many senior executives will spend extended periods working in countries other than that of their home country office. The company's Chinese operation is located in Shanghai and is staffed by a team of four expatriates, two on assignment from the United Kingdom division, one from the Danish operation and one from the Italian branch of the company. In addition, there are nine inpatriate Chinese employees working at the Shanghai offices.

All four of the expatriate staff went through a standard HR-led company programme for employees going on foreign expatriate assignments. Equally, all nine of the Chinese inpatriates have undertaken business visits to various sections of the European operations. These operations tend to be planned over a substantial period of time and employees are aware of what part of their career-cycle they may be spending a period abroad. The main focus of the study was the SME talent management HR practices and the MNC provided a triangulating case against which to question and discuss the SME practices. 


\section{Findings and Discussion}

The Findings of the paper identify a number of key emergent themes which inform and respond to the prepositions:

\section{Vignette 1 -SME HR practices accessing and recruiting talent in emerging market contexts.}

For the AE-SME, the need for local talent became apparent very early on in its dealings with the Chinese market as indicated in the following interview extracts:

Through distribution and support, of course, you are kind of handicapped [i.e. being small and yet needing an operation in China].

[Respondent - Sales Director - AE-SME]

It was largely due to pressures from competing OEM companies that the AE-SME case company decided to establish a subsidiary in China.

'The link to China was mainly because of [named employee]. I cannot quite remember how he convinced me to step into the market in China.

[Respondent - CEO - AE-SME ]

In addition to two technical service employees already working in the Chinese operation, the SME decided to run marketing activities for their products in China as well as taking decisions to recruit inpatriate talent in the form of a general manager and an accountant/marketing representative from the early stages. This was initially planned in a range of strategic meetings. Equally, as China constituted a new market for the company, it was decided that participation in industry-specific exhibitions would be an effective marketentry method. The SME collaborated with the German Chamber of Commerce which provided guidance on the organization and location of trade fairs and exhibitions. This approach provided valuable insights into the market in relation to, for example: demand for products, direct sales, the prospect of potential distributors combined with, feedback from visitors, end users and machine tool manufacturers. In addition, the AE-SME also used the exhibition to network with potential employees. For such SMEs, these sources of advice on how to enter markets and recruit talent were deemed critical by respondents. Overall, it can be seen that the SME tended to use a combination of public services and smaller-scale 
advisory services and avoided the larger scale advisory firms and mechanisms that might usually be used by MNCs:

"The lessons .... I have learnt so far is to work together with the German Chamber of Commerce because this is the support company for us. How to establish something in a foreign country needs unique consultancy. If you go with 'Large Company X' [larger well-known firm] it's going to be expensive out of our pocket".

[Respondent - CEO - AE-SME]

In particular, with the help of the German Chamber of Commerce, the case study company searched for a general manager in China. The Chamber of Commerce charged a success fee of $20 \%$ of the manager's salary and a processing fee of 2000 Euros ( $£ 1600$ Pounds). As a result, the CEO of the case study company made two trips to China to conduct interviews with six Chinese candidates who had been selected by the German Chamber of Commerce. The candidates had advanced English skills and five out of the six claimed to have studied mechanics. To the CEO's surprise, none of the candidates were able to demonstrate detailed knowledge or the ability to read simple technical drawings supplied by the CEO:

'I showed them a simple drawing and asked them 'What do you see?' Nobody could give me a correct answer. For me, I realised that they have no idea about this. They are not mechanics. I was disappointed about that and I felt insecure... I thought to myself, I made this trip, I arranged everything and now I am at a point where I have to ask myself if this is the right thing? It's too hard to find the right person. I can spend two years and search and find nobody or maybe just by coincidence I can find one. And I would like to be on the safe side and make progress in finding people.' [Respondent - CEO AE-SME]

The CEO then realised that his potential inpatriates were, in fact, potentially current 'expatriate' students on study abroad periods in Germany:

'So I needed a plan B and I searched on two sides... [The Chamber of Commerce in Shanghai] ... and one should be here, in Germany. And then I remembered that we have a university of applied sciences in [our local] 'Town $X$ ' and this university has a partnership with a Chinese university in 'Chinese City $X$ ' and they do student exchanges. They have a lot of Chinese students here. They also had an open day at the university and companies which support this can [do...] advertising there. We sent a former student there to advertise our company.' [Respondent- CEO - AE-SME] 
Thus, after unsuccessfully embarking upon a planned approach, the CEO found an alternative way and, perhaps somewhat ironically, searched for a general manager in the advanced economy home country, Germany. The local university of applied sciences organised a recruitment fair where local businesses could advertise their vacancies. It was in such a fair that a representative of the case study company was approached by a Chinese graduate who had already spent six years in Germany and was fluent in German and English. This applicant subsequently became the general manager of the case study subsidiary in China. He had originally planned to work three to four years in Germany before moving back to China however this did not fit exactly with the CEOs plan who wanted to put him through one year of intensive technical training in Germany before he returned China. Through negotiation this issue was resolved.

Furthermore, the accountant for the company was found through a series of fortunate coincidences and circumstances. Originally, the woman who was to be the accountant was employed as a translator-interpreter for the CEO during his visits to Shanghai. The overall purpose of these visits was to seek appropriately talented individuals to employ in the Chinese operation of the company. The translator-interpreter and her husband had studied in Germany. On a second visit, the CEO took his wife and requested the same translatorinterpreter after her contribution was deemed to be very professional during the first visit. During this second trip the translator-interpreter had extensive conversations with the wife of the CEO and had asked about the possibility of working for the company. This semi-informal introduction and process resulted in her becoming the accountant for the company. The initial arrangement was that she was paid through a third party. In addition, the company paid for an office space and home working. In this way informal, ad hoc and chance processes played an important role in the recruitment of key inpatriate staff in the firm.

'I wanted to hire this person immediately and I made her an offer for monthly payments but I had to do it through a partner because the Chinese subsidiary did not exist at this time.... After I decided to hire that person with a small salary per month, they offered me to hire her. [For legal constraints...] They employed the accountant instead of ...[the AE-SME]. This helped me to set up the payments for her salary. I paid the organisation in Frankfurt and they sent the money to Shanghai to pay the accountant.' [Respondent - CEO - AE-SME] 
In a further example, of unplanned and unforeseen processes, from the networking with the German Chamber of Commerce, the company found out about a German apprenticeship scheme being operated in the Shanghai region. More specifically, the scheme aimed to train Chinese technicians for German companies that operated in the Shanghai region of China. Information and contact was sought with these schemes and this process led to the next two employees being recruited. More precisely, one of the apprentice employees was recommended by the manager of the apprenticeship in China. It transpired, that the other suitable apprentice was the only one who was available in their final year - as all other apprentices had placements and thus jobs arranged.

'The apprenticeship programme there is very interesting. They offer the students .... to different companies and the companies can pay a certain amount depending on the level of education the student has. If you are in the first year, if the candidate is in the first year, you pay less. If he is in the third year, you pay a little bit more. It is like a reservation fee. You can book them. You can interview them and then say 'you are our guy, please complete your studies'. And we pay the fee not to him but to the school. And they do the same exams like in Germany. Completely the same.' [Respondent - CEO]

As part of the training and acculturation process, both did a two-month and a further sixweek placement a year later in Germany. This overall process provided a very effective means of integrating inpatriate staff into the firm.

'It was a successful approach and we had them here in Germany. Both at the same time. First they came for two months and we had to wait so long for the equipment, they had nothing to do. We couldn't give them work. We could not start but they were available. We employed them. To keep them busy, I sent them over to other companies. Like rental workers. I sent them to customers and after almost 1 year I got them back here to give them a 6-week refreshment. Then, we got the equipment and they started working.' [Respondent - CEO]

Thus, these experiences, combined with the 'home' recruitment of inpatriate staff, underscore that many of the approaches used to recruit the inpatriate staff could not really have been planned by the management of the SME. Rather, a sense of looking for links and connections close to themselves (the local university, the assigned translator-interpreter who became the company accountant) tended to be how successful solutions were delivered. Overall, these data pointed at the important role of unplanned and informal instances and situations in enabling the SME to secure appropriate talent. The inherent serendipity, ambiguity, agility 
and unpredictability of contemporary business environments (Stacey, 2010; Stokes, 2011; Shaw, 2012) is strongly reflected in the realities of talent management processes for the AESME. This is not, of course, to suggest that SMEs do not commence with forms of planning and strategy, however, the data indicate that these are quickly adjusted in order to address contingent idiosyncratic circumstances. Rather than viewing this as a 'problem', SMEs have the relatively smaller scale and size to be able to adapt and adjust in order to take advantage of changing situations.

Nevertheless, with the subsequent recruitment of the general manager and an accountant, interestingly, the relationship with the Chamber did not continue:

(On working with Chamber of Commerce at a later point)... As soon as the accountant and the general manager were involved in that (i.e. recruited), they cut them (the Chamber of Commerce) off. They don't want to work with them anymore. Too expensive, not flexible enough. That was after a couple of projects and conversations, they said, it's not a good thing.' [Respondent - CEO AE-SME]

In summary, it can be seen that the case study AE-SME adopted a planned approach which emulates MNC systems. However, early in the planned talent management process, the economic pressures caused by unsuccessful talent management searches led to the subsequent disconnection with the German Chamber of Commerce and a rapid (temporally-attitudinal) switch to a local university (in line with a spatial-attitudinal predisposition) which was able to provide subsequent inpatriate talent. It can be seen that these results and experiences underline and confirm proposition 1. Here, the AE-SME's talent management HR practices shifted away from the initial systematic and progressive approach towards the more typical approaches of an SME reflecting organic and serendipitous actions. This was demonstrated in the manner in which the AE-SME CEO became very quickly disillusioned with the approach and swiftly turned back to more familiar local European environments. Interestingly, subsequently, the Chinese inpatriate partner manager disengaged with the German Chamber of Commerce link in what can be seen as a form of reverse spatial-attitudinal act turning attention back towards the locale of Shanghai. Driven primarily by an economic rationale(which here invoked an interplay between the spatial-attitudinal and the temporal attitudinal pre-dispositions) proposition 1 marries well with proposition 2. The return of AE-SME CEO to Germany in order to undertake HR talent management processes was driven by the economic rationale of wasting resources in China, nevertheless, equally, it was also the 
organisational rationale of simply not having the staff to 'cover the ground required' in the time available. While supporting proposition 2, what is also particularly worthy of note in the data is the speed with which this spatial-attitudinal can generate switches between assisting third-parties in SME talent management searches.

The above rapid temporal and spatial transitions contrast with the MNC comparator case. Underpinned by a strong and well-resourced economic background and infused with fixed organizational structures, the MNC established HR practices which were planned and negotiated sending a steady stream of expatriates to various international operations including the office in China. Relationships tended to be stable and ongoing with third-party agencies: 'we have been working with them [a recruitment consultant firm] for many years - they are very professional and reliable.' [Senior Manager (HR) AE-MNC]. Nevertheless, the AESME, while having little choice given its limited economic resources and constrained organizational structure were unable to think of developing in this way. Nevertheless, the particular temporal and spatial-attitudinal imperatives that they embrace did afford a flexibility and agility that the MNC could not replicate. It is thus interesting that the case AESME took the decision, due to costs and a familiarity of local structures and linkages to depart from the normative MNC-style isomorphic behaviour of employing major external agencies and advisory bodies typically observed by Preece, Iles and Chuai (2011) and DiMaggio and Powell (1983). In this way, SMEs differ substantially from MNC in-house provision or longer-term third party arrangements. Moreover, in the case of the AE-MNC a number of major international recruitment agencies were engaged on a regular contractual basis in order to identify and recommend a range of prospective employees but also as a competitive device. Equally, the management development arms of these consultancies often provided training for existing employees involved in various in-company talent management programmes. An HR manager underlined:

'it is essential that we have the very best people in the market in order to ensure competitiveness - ideally we do not want such people going to competitors and once recruited we will do a lot to retain them through incentives, career planning and personal and professional development initiatives'. [Senior Manager (HR) - AE$\mathrm{MNC}]$. 


\section{Vignette 2 - SME Use and Experiences of Inpatriates and Expatriates}

In terms of using AE-SME German staff in the Chinese operation it was felt that German colleagues liaising in China with Chinese clients had powerful effects for the Chinese market however it was not possible to establish expatriate arrangements:

'We regularly send German technical employees..... You demonstrate to the customers that the Chinese market is very important... We send somebody for a week or too. That helps a lot. The main things are seeing customers, taking sales calls and they are in the company also. Looking at the equipment and having discussions about what is needed. So, there is a lot of input from that person because he/she represents the German thinking of our company....' [Respondent- Sales Director AE-SME]

'Sending somebody over for a longer period of time (6-12 months) is not possible, unfortunately. I would do it immediately but I cannot do it, it's too big of a change for the person and I cannot afford it. It would be the best way to send somebody for a longer time. That is what many companies do successfully.' [Respondent- CEO-AESME]

For the AE-SME case study company, this situation was driven by a combination of economic and organizational factors. Economically, the company, due to the high costs of establishing long-term expatriates in the Chinese operation was clearly a concern. However, it is interesting to note that it was primarily, organizational rationale which was prompting behaviour in a temporal-attitudinal manner. In temporal operational terms, only short interventions by 'visiting expatriates' were considered feasible for the AE-SME and this operated in a series of periodic visits which attempted to provide the impression of presence of German staff. These arrangements were often made in a relatively ad hoc and short timeframe manner (in comparison to the AE-MNC more planned approaches). This supported proposition 3 which suggested that SME HR talent management practices follow short-term expatriate and inpatriate staff configurations. Moreover, the actions of the AE-SME supported the assertion by Collings et al. (2007) that it is crucial to develop alternative approaches to international assignments which reflect an organization's particular situation. The behaviour of the AE-SME in relation to expatriates differed substantially from AEMNC. Here, the expatriates were very much a semi-permanent element of the Chinese operation. It was noted that this created a very different atmosphere in the Chinese partnership and operation. Overall, the atmosphere was more 'corporate' and reminiscent of 
the base 'home' office. Nevertheless, in line with Cerdin and Brewster (2014) identify divisions and boundaries between the expatriates and the Chinese culture and the expatriates and the inpatriates were still discernible: 'Look, we are different. That's just a fact. We work together on tasks but often we see the issues differently and they [the inpatriates] often turn to local contacts to progress problems and projects rather than work it through the company and that can be quite frustrating.' [expatriate Executive Manager - AE-MNC]

However, in relation to the above development of proposition 3 we can also identify aspects of spatial-attitudinal behavioral dimensions in operation. In spatial operational terms case AE-SME staff also did not wish to be relocated long-term to China. This echoes back to the importance of geographical 'proximity' and sense-making (Weick, 1995) to the German firm AE-SME staff mindsets pointed at previously by, for example, proposition 2. Equally, in relation to DE-SME's decision not to use expatriates, the data supported Farndale's et al. (2010) observation that the given target emerging economy (i.e. the Chinese market) was considered too differentiated in terms of language and culture to use expatriates successfully. This linked to the effects noted by Al Ariss (2014) that locals are less likely to work and socialise with expatriates. Overall, the data indicate that it was perceived that using long-term German expatriates in China would be a cultural faux pas, because of culture differences and the challenging language barrier:

\footnotetext{
'Also, the general manager, who was here for one year to receive the training, he also gave Chinese lessons to professionals from other companies who regularly go to China. Of course, their language abilities are not excellent but it's good enough to start.' [Respondent-Sales Director - AE-SME]

'Most of these [expatriate] people were in the middle and lower management level. Except for Company Y, I don't really know any company in China where the top manager is not a Chinese person. This is cultural as well.' [Respondent- Sales Director - AE-SME]

'There are many German people working in China but I have never really met somebody who speaks Chinese fluently. One time there was the manager of that building, the German centre in Shanghai. (...). He was the only one I have ever met in 7 years.' [Respondent - CEO - AE-SME]
}

As noted, in MNC contexts, Cerdin and Brewster (2014) underscored that expatriates may not have a sense of identity with the overseas organisation and thus do not realise their high 
potential. In the case of AE-SME HR practice in the emerging economy context under examination the approach of inpatriates and short-term expatriate visits avoided these effects. This reinforces a point of learning that SMEs can offer to MNC as alluded to by Harvey (2010):

'It has been argued that flexipatriate and inpatriate candidates are widely ignored by the IHRM departments of many MNCs, yet these assignments - which are a major component of global, staffing for large and small organizations - contribute to the development of global competence far more than expatriate assignments.' (Harvey, 2010).

On a final point, the AE-SME case data also indicated the active role that the inpatriates also played in seeking out developed economy organisations. A number of Chinese employees indicated that they had specifically targeted a German company when searching for a job. As noted above, the Accountant and the General Manager had spent many years studying in Germany and considered it as an advantage to work for a German company in China. Furthermore, none of the employees in the Chinese partner organisation had ever worked for a Chinese company previously. A further reason for targeting a German company, by the Chinese inpatriates, was the abundance of German companies in the region of Shanghai and their reputation and career development potential.

'I know how the German guys work and think, and I also know what I may offer them in Chinese market. So, it was my original plan to work in a German company.' [Respondent-Chinese General Manager AE-SME]

\section{Vignette 3 - Inpatriate Acculturisation: Processes and Challenges}

The importance of building trust, mutual understanding and belongingness for employees during change and transformation (Bhatnagar et al., 2010) in the case of international expansion was also considered a crucial aspect for success in the AE-SME case. Without this, it was feared that the Chinese employees would soon depart from the organisation in order to find a position within a Chinese company. Indeed, this as to resurface as a constant concern for the AE-SME. Thus, while the AE-SME case data add to the body of literature that finds potential benefits in transferring employees to corporate HQs and then returning into the home emerging economy context (Reiche, 2012), nevertheless, in spite of these efforts to 
acculturate the inpatriates, there was evidence of the occurrence of what herein is termed as 're-acculturisation', or, a returning towards the sensemaking ways of an original culture (Weick, 1995). The initial period of one year spent by the newly recruited general manager at the headquarters in Germany was considered crucial by the CEO. The original purpose was to provide the new general manager with the product-specific technical knowledge, which would enable him to respond to customer requests personally in China. In addition to this, the CEO realised that exposure to, and integration into, the corporate culture at the headquarters, developed around the tacit knowledge of the corporate structure and communication channels and professional relationships were significant success factors in employing the new member of staff in the new location in China.

"Without the one year experience in Germany there would have been no chance for him to do this job in China... If I would do it again, I would do it one and a half years or two years." [Respondent- CEO- AE-SME]

".... it was a huge advantage to have him working here in my department. He learned from scratch how things are done here, how the system works, the discount structure, the products. He has an excellent knowledge about that. So now he can take this and match it to the Chinese market because he is ... [indigenous] Chinese...."

[Respondent- Sales Director AE-SME]

Thus, the temporary 'expatriate' experience provided the newly recruited inpatriate Chinese general manager with an apparent solid grounding in the firm's organisational culture, and equally importantly, background German national culture. The data illustrate the intense efforts that the economically resource-limited AE-SME undertook to acculturate inpatriate colleagues. The six-year long study period experience in Germany had equipped the General Manager with deep tacit knowledge surrounding German work ethics, culture and productivity. However, it was highlighted in the data that this 'conditioning' had to receive ongoing input and management by staff at the AE-SME. Frequent visits, phone calls and email correspondence had to be maintained at all times in order to ensure that the German country standards were maintained as there was a felt-risk that the General Manager was occasionally losing his German perspective. A matter of months following the return of the General Manager to China, there were indications that he was beginning to apply the German DE-SME approaches he had learned, however, on occasion, there were also signs that he was re-adopting his emerging economy Chinese culture: 
'You sometimes have to control him, to bring him down and say "Look, this is the way we are doing this". And, he knows it, he has studied here for many years in Germany and he is now back in China and he is now transforming back to become more Chinese. The German way is disappearing.' [Respondent-Sales Director AESME]

'After the general manager returned to China, we told him that he is turning Chinese again and he is not our German colleague anymore. Our Chinese partners, on the other hand, always say he was too long in Germany. But, he is doing well and it is a good fit but the market is not easy at the moment.' [Respondent-CEO AE-SME]

'So it was completely the opposite of what I have suggested to him and advised him to do. I think this is because he has not much time, I am aware of that. At that time it was very difficult but when he talked to the company on the phone, he got the Chinese solution somehow. Germans would like to do it, you know. We'd say, we need that test equipment.' [Respondent- Sales Director - AE-SME]

From the perspective of the AE-SME Sales Department, having a General Manager who was also responsible for all the sales activities had certain limitations. Too many management responsibilities led to delays on the sales aspects of the Chinese operation. The AE-SME Sales Director would advise the Chinese General Manager to delegate more tasks to the onsite customer service representative but this was not possible because she was also the Accountant for the subsidiary. Furthermore, both the AE-SME CEO and Sales Director mentioned that the time difference between Germany and China caused considerable stress for the Chinese General Manager who often has to continue working late at night in addition to the time spent on the job in the day. In contrast, in the case of the AE-MNC case, while, as evidenced above in Vignette 2, there were some tendencies for inpatriates to connect with the environment external to the company in order to achieve tasks, the influence of a larger MNC culture nevertheless played a potent role. Here, it was evident that the larger scale economic and organisational resources were influencing and requiring corporate 'compliance' in inpatriate behaviour. The more extensive and replete AE-MNC organisational context thus created a 'world' from which it was difficult to escape than that AE-SME. as a consequence, re-acculturisation was more prevalent in the latter.

The issue of re-acculturisation, when viewed from the perspective of the inpatriate, highlights that the talented individual may have to 'walk a tightrope' between the cultures involved. This balancing act may demand a lot of the individual and aligns with the complexities of culture identified by Lenartowicz and Johnson (2007). Moreover, it underscores the 
challenges of managing talent (inpatriate or otherwise) from a distance. Such management control may be more evidently possible in a MNC environment with formalised corporate mechanisms and procedures, however, the economic and organizational rationales governing SME HR practices mean that less-structured and small-scale management teams within the SME environment may make it difficult to exert such control in a consistent manner. Following Proposition 4, it can be seen that such swings, or oscillation, towards what can be termed 're-acculturisation' are a potent force in the complex and changeable SME-inpatriate relationship dynamic. Thus, what may be termed 'acculturisation-re-acculturisation oscillation' echoes the agility and flexibility that are an innate part of the SME experience and wider contemporaneous business environmental conditions (Stacey 2010, Shaw 2010, 2012). The oscillation between acculturisation and re-acculturisation can be a considerable issue SMEs when a firm has invested economically (and indeed emotionally) extensively in acculturisation in the first instance.

Headhunting (and poaching by Chinese firms) was also seen as a legitimate and popular approach to hire skilled employees and was a force driving re-acculturisation. In order to attempt to prevent this and to retain employees, incentive schemes were perceived to be very successful in increasing loyalty to the firm:

'[We need...] a proactive person, who can be sent to customers, who can present the products and represent the company and all that, so he will get interest and the orders. We could find this guy in China. But the real difficulty is that we find someone who is really technically capable to understand our products and its applications. This is the real issue here.....It's just a question of a little bit more pay or if you have a special incentive programme, if you are able to pay some part of their rent or pension or whatnot. This is pretty popular in China, to keep people in the company.'

[Respondent-Sales Director - AE-SME]

'You have to be aware that the Chinese want to earn money. So, there is no other retention, to hold them in the company. They will go sooner or later. If they get $10 \%$ more pay from another company, they will go..... Chinese employees have no loyalty to a company. A company is not a person in their mentality. In the Chinese mentality, a company is not a human being, it's just a name. They have loyalty to persons, to people, to me, to the team. This loyalty is very important to keep the team together." [Respondent - CEO - AE-SME]

'If I look to our own guy, there is risk too. So far, we are not really successful. He spends a ton of hours. He has definitely some advantage of his language and his 
experience. He could be headhunted very quickly because he knows a lot of companies through the networking he is doing. He loves to do the networking. Of course, to sell our products at the moment but something like this could happen. For example, company $\mathrm{Z}$, which is a supplier for some tools that we use in our warehouse shop and they made him an offer. He said no. He told me.'

[Respondent- Sales Director - AE-SME]

The retention of employees represented a potential risk for the AE-SME and was carefully considered in the longer-term recruitment plans. This is why two technicians were recruited, despite the fact that only one was needed. This over-staffing of inpatriates represented a deliberate policy in spite of the economic rationale in operation:

'If they work a couple of years for a German company, they have a very good reference. They can get any job in China. Hopefully, they won't go.... Retention is massively important! If one of them quits the job, it's a big loss. Finding a new one, the investment is very high and all the knowledge it takes. This is the reason why I hired two people. Knowing that I would probably only have the work for one, I have another one as a back-up, just in case.' [Respondent-CEO AE-SME]

Even though there is an extensive emphasis on the recruitment and retention of technicians, there were less contingency plans available were the Chinese General Manager to leave the organisation.

'....(laughs) 'I would send the sales director over for two years (laughs) or pack my own suitcase.' 'That would be a very big problem at the moment. It's dangerous. I have no plan B for that. We would have to think new. Start thinking about that just in case.' [Respondent - CEO - AE-SME]

In summary, Vignette 3 highlights the powerful issue of retention of talent and the challenge of building loyalty and commitment for the SME. In some environments (such as the Chinese case) certain factors, such as financial incentive, may play a disproportionately strong role in luring the inpatriate employee away from an SME. Here, higher pay rates of larger MNCs and national major corporations are likely to provide a strong pull. Perhaps an alternative option for an SME would be to accept the mindset and 'inevitability' that both inpatriate and locally sourced talent will be almost impossible to retain in the long-run and that these staff will move on as the SME cannot compete with the economic power or the organisational career options that an MNC can probably offer. When viewed in this manner, talent becomes a resource that invariably 'flows' through the organisation. This is in-keeping with the 
approach advocated by Cappelli (2008) who suggests that the manager's task is to work with the 'flow of talent' that enters, progresses through and then exits the organisation. In essence, therefore, SME managers in particular may need to act as enablers and facilitators who control the direction and pace of talent moves through the organisation. From this perspective, it follows that SMEs should accept that staff turnover will be high, and concentrate their HR practices and scarce resources on identifying, recruiting (when required), and, managing the flow of talent rather than trying to invest economic resources in preventing talent leaving.

\section{Conclusion}

The paper has developed and employed economic and organisational, and consequent behavioral, rationales in order to structure an approach to more fully understanding HR talent management practices in emerging economy contexts. The specific SME case identified a German SME setting up partnership arrangements in the Chinese emerging economy. The complex nature of global staffing identified by Collings et al. (2007) is reflected within the SME case study provided. The case data underline that although SMEs are likely to, in an initial instance, undertake systemic formal forms of planning that emulate, to some degree, MNC processes and practices. Based on the findings, attempts by SMEs to adhere to normative MNC models seem prone to rapid adjustment towards more proximate, local and serendipitous methods in the search for global talent within strategic partnerships in emerging markets. Thus, SMEs, affirming propositions 1 and 2, appear, initially, to embark on mimetic and isomorphic behaviour in HRM practices for talent management (DiMaggio and Powell, 1983; Preece, Iles and Chuai, 2011) however, following a period of formal planning and action, tend to engage with a wide and varied range of third parties as they rapidly move into more organic and opportunistic patterns of behaviour. In building up the staff complement, it was found that SMEs tend to opt for configurations of inpatriates and short-term expatriate visits. This was in large part driven by the governing and constraining SME economic rationale which could not support the costs of long-term expatriation and serve to underpin and evidence proposition 3. However, it was complemented by an organizational-behavioral rationale linked to spatial-attitudinal aspects of developed economy German employees who equally did not wish to live in China for a long period. Acculturisation (into the SME culture and the national cultural context from which an inpatriate originates) for new employees was 
clearly viewed as a deliberate and essential process. The SME company actively undertook this and aimed to create a 'new' normative way of behaviour for the inpatriates. This created a form of dual cultural-facing employee able simultaneously to comprehend the developed economy national culture and to apply and interface this with his or her indigenous emerging culture. Acculturisation operated in strong dynamic and tension with re-acculturisation and this was explicated, explored and demonstrated by Proposition 4. The experience of the inpatriate General Manager of the Chinese operation returning towards Chinese patterns of behaviour was a source of considerable frustration for the German office. Re-acculturisation seems to be a major challenge in the SME context where organizational rationale is more weakly formed than MNC and there is not the over-arching and all-embracing corporate culture of a large corporate entity in place. Despite earlier extensive cultural immersion and ongoing reinforcement from the German office seemed to be a powerful draw on economic and behavioural resources for the SME management.

The paper's argument also concurs with Al Ariss's (2014) suggestion that it is essential to understand the local parameters relating to expatriation, and, herein, the argument furthermore suggests that this stretches to the recruitment of inpatriates as well. Our study contributes to the recent call to gain a fine-grained understanding of talent management beyond the MNC context (Collings, Scullion, and Vaiman, 2015). The case herein values the inpatriation of host country nationals as a means of increasing and developing international management talent (Harvey, 1999). Moreover, although there are indeed fewer boundaries as the function of talent management focuses more on the global market (Al Ariss, 2014), the case study, and its particular contextual nature, highlights that the floodgates for global talent recruitment have not opened for SMEs to the extent that might be portrayed in alternative accounts on MNCs. Thus, while talent overall may seem to be plenty and an MNC-style scan and search process may identify and access this, for the individual SME in search of talent, the immediate character of its scanning and proximate 'locality' means that it does not 'see' or identify the wider pool of talent so readily and therefore for the SME there is the impression of a distinct scarcity of talent available. Overall, the evident challenge of SME staff retention may mean that the management team of the developed economy SME operating in an emerging market may be obliged to accept and see as inevitable the cyclical nature of talent recruitment, retention and loss in the medium to longer-term operating in tandem with processes or re-acculturisation. This implies that, depending on the cultural factors in any given national context, the ongoing SME search for talent, and the process of 
talent succession management, becomes an unavoidable aspect of the strategic partnership in an emerging market context.

With a view to managerial implications, there is a need for managers to recognise the differing role of spatial-attitudinal and temporal attitudinal predispositions and the drivers of these in relation to decision-making and ultimate consequences for the business. This point draws attention to a need to recognise underlying normative spatial and temporal trajectories for SMEs and their implications for talent management - rendered all the more complex when operating in the cultural environment of an emerging market. The underlying normative temporal mechanisms point at rapid movement between notional 'planned' stages of talent recruitment and management to serendipitous, agile and flexible aspects of operation. This further highlights the need for organisations to develop both internal and external HR flexibility as they deal with cultural differences (Sarala, Junni, Cooper and Tarba, 2014). Equally, and, in parallel, the paper points at the role of spatial drivers which ultimately tend to lead to SME management making sense (Weick, 1995) of economic and organizational imperatives through local and proximate rather than remote solutions. Moreover, there is a need to be aware of, and to manage, risks associated with acculturisation-re-acculturisation oscillation among inpatriates. In an SME context, this particular tension is likely to be powerfully felt due to the imperatives of the economic and organizational rationale of which the firm must remain mindful.

In conclusion, this paper clearly indicates that, HRM practices in relation to talent management in an emerging context are likely to be operating in a considerably more organic, opportunistically and proximately informed environment and transient set of strategic partnerships to those normatively engaged in by MNCs. Although this research has focused on specific cases and contexts this will provide future researchers to conduct work in a number of areas. These may include, although not exclusively: further evaluation of the novel conceptual model generated in the paper in relation to differing business sector, geographic, and indeed activity/topic (i.e. beyond talent management) contexts; a deepening of the understanding of acculturisation-re-acculturisation oscillation; and, expansion of the understanding of the dialectic between spatial and temporal behavioural factors in SME settings. This paper adds to knowledge and understanding of a rapidly changing landscape characterised by volatility and complexity. This contribution may well help in supporting practitioners in achieving talent strategies that enhance organisational performance. 


\section{References}

Achanga, P., Shehab, E., Roy, R. and Nelder, G. (2006) Critical success factors for lean implementation within SMEs. Journal of Manufacturing Technology Management, 17 (4), 460-471.

Agrawal, S., 45 (3), 481 - 491 (2010) Talent management Model for Business Schools: Factor Analysis. The Indian Journal of Industrial Relations 45 (3), 481-491.

$\mathrm{Al}$ Ariss, A. (2014) Voicing experiences and perceptions of local managers: expatriation in the Arab Gulf. The International Journal of Human Resource Management, 25 (14), 1978-1994.

Bacon, N. and Hoque, K. (2005) HRM in the SME sector: valuable employees and coercive networks. The International Journal of Human Resource Management, 16(11): 1976-1999.

Barret, R. and Mayson, S. (2007) Human Resource Management in Growing Small Firms. Journal of Small Business and Enterprise Development, 14 (2), 307-320.

Beaver, G. (2002) Small business, entrepreneurship and enterprise development. Harlow: Pearson Education Limited.

Bhatnagar, J., Budhwar, P., Srivastava, P. and Saini, D.S. (2010) Organizational change and development in India: A case of strategic organizational change and transformation. Journal of Organizational Change Management, 23 (5), 485-499.

Bidwell, M. and Keller, J. (2013), Within or without? How firms combine internal and external labor markets to fill jobs, Academy of Management Journal, Published online before print October 23.

Bonet, R., Cappelli, P. and Hamori, M. (2013), Labor market intermediaries and the new paradigm for human resources, The Academy of Management Annals, 7, 341-392.

Breaugh, J.A. (2013), Employee recruitment, Annual Review of Psychology, 64, 389-416.

Burgelman, R.A. (2011), Bridging history and reductionism: A key role for longitudinal qualitative research, Journal of International Business Studies, 42, 591-601.

Burns, P. (2001) Entrepreneurship and Small Business. London: Palgrave Publishing.

Cameron, S. and Price, D. (2009) Business Research Methods: A Practical Approach. London: CIPD.

Cappelli, P. (2008) Talent on demand: managing talent in an age of uncertainty. Boston, Mass: Harvard Business Press.

Cappelli, P. and Hamori, M. (2014), Understanding executive job search, Organization Science, 25, 1511-1529.

Caprar, D.V. (2011), Foreign locals: A cautionary tale on the culture of MNC local employees, Journal of International Business Studies, 42, 608-628.

Cerdin, J.-L. and Brewster, C. (2014) Talent management and expatriation: Bridging two streams of research and practice. Journal of World Business, 49 (2), 245-252.

Collings, D.G., Doherty, N., Osborn, D. and Luethy, M. (2011) Understanding and Supporting the Career Implications of International Assignments. Journal of Vocational Behaviour, 78 (3), 361-371.

Collings, D.G. and Mellahi, K. (2009) Strategic talent management: What is it and how does it matter? Human Resource Management Review, 19, 304-313.

Collings, D.G., Scullion, H. and Morley, M.J. (2007) Changing patterns of global staffing in the multinational enterprise: Challenges to the conventional expatriate assignment and emerging alternatives. Journal of World Business, 42 (2), 198-213.

Collings, D.G. (2014), Integrating global mobility and global talent management: Exploring the challenges and strategic opportunities, Journal of World Business, 49, 253-261.

Collings, D.G., Scullion, H. and Vaiman, V. (2015) Talent management: Progress and prospects. Human Resource Management Review, 25, 233-235.

Cooke, F.L. (2009) A decade of transformation of HRM in China: A review of literature and suggestions for future studies. Asia Pacific Journal of Human Resources, 47 (1), 6-40.

Cooper, C.L. and Burke, R.J. (2011) Human resource management in small business: Achieving peak performance. Cheltenham: Edward Elgar. 
Czarniawska, B. (1998) A Narrative Approach to Organization Studies, Sage Publications, London.

Dimaggio, P.J. and Powell, W.W. (1983) The iron cage revisited: Institutional Isomorphism and collective rationality in organizational fields. American Sociological Review, 48 (2), 147-160.

Edmondson, A.C. and McManus, S.E. (2007), Methodological fit in management field research, Academy of Management Review, 32, 1246-1264.

Eisenhardt, K.M. and Graebner, M.E. (2007), Theory building from cases: opportunities and challenges, Academy of Management Journal, 50, 25-32.

Farndale, E., Scullion, H. and Sparrow, P. (2010) The role of the corporate HR function in global talent management. Journal of World Business, 45 (2), 161-168.

Feng Hsu Liu , (2014) OEM supplier impact on buyer competence development. Journal of Strategy and Management. 7(1), $2-18$.

Festing, M., Schäfer, L. and Scullion, H. (2013) Talent management in medium-sized German companies: an explorative study and agenda for future research. The International Journal of Human Resource Management, 24(9): 1872-1893.

Festing, M. and Schäfer, L. (2014) Generational challenges to talent management: A framework for talent retention based on the psychological-contract perspective. Journal of World Business, 49 (2), 262-271.

Furusawa, M. and Brewster, C. (2014) The bi-cultural option for global talent management: The Japanese/Brazilian Nikkeijin example. Journal of World Business.

Gabriel, Y. (2000), Storytelling in Organizations: Facts, Fictions and Fantasies, Oxford University Press, Oxford.

Gabriel, Y. (2004), Myths, Stories and Organizations: Pre-Modern Narratives for Our Times, Oxford University Press, Oxford.

Gélinas, R. and Bigras, Y. (2004) The Characteristics and Features of SMEs: Favorable or Unfavorable to Logistics Integration? Journal of Small Business Management, 42 (3), 263 278.

Gomes, E., Weber, Y., Brown, C. and Tarba, S.Y. (2011). Mergers, acquisitions and strategic alliances: Understanding the process. Basingstoke, UK: Palgrave Macmillan.

Gray, C. (2004) Management Development in European Small and Medium Enterprises. Advances in Developing Human Resources, 6 (4), 451-469.

Graebner, M. E. (2004). Momentum and serendipidity: How acquired firm leaders create value in the integration of technology firms. Strategic Management Journal, 25(8-9), 751-777.

Graebner, M.E. and Eisenhardt, K.M. (2004). The other side of the story: Acquisition as courtship and governance as syndicate in entrepreneurial firms. Administrative Science Quarterly, 49, 366403.

Gubrium, J., Holstein, J., Marvasti, J. and Mckinney, K. (2012) The Sage Handbook of Interview Research: The Complexity of the Craft. London: Sage.

Handy, C.B., Gordon, C., Gow, I. and Randlesome, C. (1988) Making Managers. London: Pitman.

Harney, B. and Dundon, T. (2006) Capturing complexity: developing an integrated approach to analysing HRM in SMEs. Human Resource Management Journal, 16(1): 48-73.

Harrison, R. (2002) Learning and Development 3rd ed. London: Chartered Institute of Personnel and Development Publishing.

Harvey, M., Mayerhofer, H., Hartmann, L. and Moeller, M. (2010) Corralling the "Horses" to Staff the Global Organization of 21st Century. Organizational Dynamics, 39 (3), 258-268.

Harvey, M.G., Speier, C. and Novicevic, M.M. (1999) The role of inpatriation in global staffing. International Journal of Human Resource Management, 10 (459-476).

Hippler, T. (2009) Why do they go? Empirical Evidence of Employees Motives for Seeking and Accepting Relocation. International Journal of Human Resource Management, 20 (6), 1381 1401. 
Hutchinson, V. and Quintas, P. (2008) Do SMEs do knowledge management? or Simply manage what they know? International Small Business Journal, 26 (2), 131-154.

Ifc International Finance Corporation (2013) World Bank. [Accessed 11.12].

Iles, P., Chuai, X. and Preece, D. (2010) Talent Management and HRM in Multinational companies in Beijing: Definitions, differences and drivers. Journal of World Business, 45 (2), 179-189.

Kotey, B. and Slade, P. (2005) Formal Human Resource Management Practices in Small Growing Firms. Journal of Small Business Management, 43 (1), 16-40.

Kramer, R.M. (ed.) (2006) Organisational Trust: Progress and Promise in Theory and Research, Introduction in Organizational Trust: A Reader. Oxford: Oxford University Press.

Langley, A., Smallman, C., Tsoukas, H. and Van de Ven, A.H. (2013), Process studies of change in organization and management: unveiling temporality, activity, and flow, Academy of Management Journal, 56, 1-13.

Lappelainen, J. and Niskanen, M. (2014) Behavior and attitudes of small family firms towards different funding sources, Journal of Small Business and Entrepreneurship, 26(6), 579-599.

Lenartowicz, T. and Johnson, J.P. (2007) Staffing managerial positions in emerging markets: a cultural perspective. International Journal of Emerging Markets, 2 (3), 207-214.

Lewis, K. (2015) Enacting entrepreneurship and leadership; a longitudinal exploration of gendered identity work, Journal of Small Business Management, published on-line $28^{\text {th }}$ April.

Lewis, R. and Heckman R., J. (2006) Talent Management: A Critical Review. HR Management Review, 16, 139-154.

Lindblom, C. (1959) The science of muddling through, Public Administratin Review, 19(2): 79-88.

Linstead, S, Lilley and Fulop, L. (2009) Management and Organization: A Critical Text, Basingstoke, Palgrave-Macmillan.

Lockwood, N. (2006) Talent Management: Driver for Organizational Success. SHRM Research Quarterley, (2).

Mazzarol, T. (2003) A model of small business HR growth management. International Journal of Entrepreneurial Behaviour \& Research, 1 (27-49).

Melkonian, T., Monin, P. and Noorderhaven, N. G. (2011). Distributive justice, procedural justice, exemplarity, and employees' willingness to cooperate in M\&A integration processes: An analysis of the Air France-KLM merger. Human Resource Management, 50 (6), 809-837.

Meyskens, M., Von Glinow, M.A., Werther, J.W.B. and Clarke, L. (2009) The paradox of international talent: alternative forms of international assignments. The International Journal of Human Resource Management, 20 (6), 1439-1450.

Minbaeva, D. and Collings, D.G. (2013) Seven myths of global talent management. The International Journal of Human Resource Management, 24 (9), 1762-1776.

Monin, P., Noorderhaven, N., Vaara, E. and Kroon, D. (2013), Giving sense to and making sense of justice in postmerger integration, Academy of Management Journal, 56, 256-284.

Nardon, L. and Steers, R.M. (2008) The New Global Manager. Organizational Dynamics, 37 (1), 47 59.

Nieto, M-J., Santamaria, L and Fernandez, Z. (2013) Understanding the Innovation Behavior of Family Firms, Journal of Small Business Management, 53(2): 382-399.

Penrose, E.T. (1959) The Theory of the Growth of the Firm. Oxford: Oxford University Press.

Phillips, N. and Oswick, C. (2012), Organizational discourse: Domains, debates, and directions, The Academy of Management Annals, 6, 435-481.

Preece, D., Iles, P. and Chuai, X. (2011) Talent management and management fashion in Chinese enterprises: exploring case studies in Beijing. The International Journal of Human Resource Management, 22 (16), 3413-3428.

Riad, S. and Vaara, E. 2011. Varieties of national metonymy in media accounts of international mergers and acquisitions. Journal of Management Studies, 48(4): 737-771. 
Riad, S., Vaara, E. and Zhang, N. 2012. The intertextual production of international relations in mergers and acquisitions. Organization Studies, 33(1): 121-148.

Ready, D. (2009) Forging the New Talent Compact. Business Strategy Review, Summer.

Reiche, B.S. (2012) Knowledge Benefits of Social Capital upon Repatriation: A Longitudinal Study of International Assignees. Journal of Management Studies, 49 (6), 1052-1077.

Reiche, B.S., Kraimer, M.L. and Harzing, A.-W. (2011) Why do international assignees stay? An organizational embeddedness perspective. Journal of International Business Studies, 42, 521544.

Reiche, S. (2006) The Inpatriate Experience in Multinational Corporations. International Journal of Human Resource Management, 17 (9), 1572-1590.

Schweizer, L. (2006). Organizational integration of acquired biotech companies into pharmaceutical companies: The need for a hybrid approach. Academy of Management Journal, 48(6), 10511074.

Siggelkow, N. (2007) Persuasion with Case Studies. Academy of Management Journal. 50(1):20-24.

Silverman, D. (2010) Doing Qualitative Research. London: Sage.

Stanworth, J. and Gray, C. (eds.) (1991) Bolton 20 Years On: Small firms in the 1990s. London: Paul Chapman Publishing.

Stokes, D. and Wilson, N. (2006) Small business management and entrepreneurship, 5th ed. London: Thomson Learning.

Shaw, P. (2010), Defining Moments: Navigating through Business and Organizational Life, Basingstoke, Palgrave Macmillan.

Shaw, P. (2012), The Age of Agility, London, Praesta Partners.

Stacey, R. (2010) Complexity and Organizational Reality: Uncertainty and the Need to Rethink Management after the Collapse of Investment Capitalism, London, Routledge.

Stokes, P. (2011) Critical Concepts in Management and Organization Studies, Basingstoke, PalgraveMacmillan.

Tarique, I. and Schuler, R.S. (2010) Global talent management: Literature review, integrative framework, and suggestions for further research. Journal of World Business, 45 (2), 122-133.

Teerikangas, S. (2012). Dynamics of acquired firms pre-acquisition employee reactions. Journal of Management, 38 (2), 599-639.

Teerikangas, S., Very, P. and Pisano, V. (2011). Integration managers' value capturing role and acquisition performance. Human Resource Management, 50 (5), 651-683.

Thorpe, R., Jones, O., Macpherson, A. and Holt, R. (2008) The Evolution of Business Knowledge in Smaller Firms IN: Scarborough, H. (ed.) In The evolution of business knowledge. Oxford: Oxford University Press.

Tocher, N. and Rutherford, M. W. (2009) Perceived acute human resource management problems in small and medium firms: an empirical examination. Entrepreneurship Theory and Practice, 33(2): 455-479.

Tymon, W.G., Stumpf, S.A. and Doh, J.P. (2010) Exploring talent management in India: The neglected role of intrinsic rewards. Journal of World Business, 45 (2), 109-121.

Valverde, M., Scullion, H. and Ryan, G. (2013) Talent management in Spanish medium-sized organisations. The International Journal of Human Resource Management, 24 (9), 18321852.

Vaara, E. and Tienari, J. 2011. On the narrative construction of multinational corporations: An antenarrative analysis of legitimation and resistance in a cross-border merger. Organization science, 22(2): 370-390. 
Voordeckers, W., Van Gils, A., and Van de Heuvel, J. (2007) Board Composition is Small and Medium-Sized Family Firms, Journal of Small business Management, 45(1): 137156.

Warner, M. (2012) Whither Chinese HRM? Paradigms, models and theories. International Journal of Human Resource Management, 23 (19), 3943-3963.

Weber, Y. and Fried, Y. (2011a). The role of HR practices in managing culture clash during the postmerger integration process. Human Resource Management, 50 (5), 565-570.

Weber, Y. and Fried, Y. (2011b). The dynamic of employees' reactions during post-merger integration process. Human Resource Management, 50 (6), 777-781.

Weber, Y. and Tarba, S.Y. 2010. Human Resource Practices and Performance of Mergers and Acquisitions in Israel, Human Resource Management Review, 20, 203-211.

Weber, Y., Tarba, S.Y. and Reichel, A. (2009). International mergers and acquisitions performance revisited - The role of cultural distance and post-acquisition integration approach implementation. Advances In Mergers and Acquisitions, Vol. 8, 1-18.

Weber, Y., Tarba, S.Y. and Reichel, A. (2011). A model of the influence of culture on integration approaches and international mergers and acquisitions performance. International Studies of Management and Organization, 41(3), 9-24.

Weber, Y., Tarba, S. Y., and Oberg, C. 2014. A Comprehensive Guide To Mergers \& Acquisitions: Managing the Critical Success Factors Across Every Stage of the M\&A Process. New York, USA: Pearson \& Financial Times Press.

Weick, K. (1995) Sensemaking in Organizations. Thousand Oaks(CA), Sage Publications.

Wilson, J.F. and Thomson, A.W.J. (2006) The making of modern management: British management in historical perspective. Oxford: Oxford University Press.

Xing, Y., Liu, Y., Tarba, S.Y. and Cooper, C.L. (2014 forthcoming) Intercultural influences on managing African employees of Chinese firms in Africa: Chinese managers' HRM practices. International Business Review. 10.1016/j.ibusrev.2014.05.003

Yao, C. (2014) The impact of cultural dimensions on Chinese expatriates' career capital. The International Journal of Human Resource Management, 25 (5), 609-630.

Zhang, Z., Ahammad, M. F., Cooper, C., Glaister, K.W., and Wang, J. (2015).The impact of leadership style on talent retention during M\&A integration: Evidence from MNEs in China. International Journal of Human Resource Management; 26 (7), 1021-1050.

Zheng, C., Morrison, M. and O'Neill, G. 2006. An empirical study of high performance HRM practices in Chinese SMEs. The International Journal of Human Resource Management, 17(10): 1772-1803.

Zhu, C.J., Thomson, S.B. and Cieri, H.D. (2008) Human Resource Management. A retrospective and prospective analysis of HRM research in Chinese firms: Implications and directions for future study, 47 (1), 133-156. 